\title{
Coarctation of Aorta Presenting as Spontaneous Subarachnoid Hemorrhage in a Young Female: A Case Report of a Rare Clinical Entity
}

\author{
Huliyurdurga Srinivasa Setty Natraj Setty ${ }^{\mathrm{a}, \mathrm{b}}$, Patil Shivanand ${ }^{\mathrm{a}}$, Pandurangan Narendhiran ${ }^{\mathrm{a}}$, \\ Patil Veeresh ${ }^{\mathrm{a}}$, Kharge Jayashree ${ }^{\mathrm{a}}$, Tagatagere Ramegowda Raghu ${ }^{\mathrm{a}}$, Patil Rahul ${ }^{\mathrm{a}}$, \\ Bachahalli Krishnanayak Geetha ${ }^{a}$, Raj Sathwik ${ }^{a}$, \\ Cholanahalli Nanjappa Manjunath ${ }^{\mathrm{a}}$
}

\begin{abstract}
Coarctation of the aorta $(\mathrm{CoA})$ is one of the common congenital cardiovascular diseases. CoA can be diagnosed over a wide range of ages, with varying degrees of severity, and in various presentations. The most common presenting age of $\mathrm{CoA}$ is $3-6$ months with only a small proportion of adolescents and adults diagnosed with primary aortic coarctation of the aorta. Intracranial aneurysms that undergo spontaneous rupture causing subarachnoid hemorrhage (SAH) are rare in young patients with CoA. We report a 22-year-old young female successfully underwent right pterional craniotomy, clipping of aneurysm and balloon dilatation of coarctation of the aorta.
\end{abstract}

Keywords: Coarctation of the aorta; Subarachnoid hemorrhage; Aneurysms

\section{Introduction}

Coarctation of aorta complicated by subarachanoid hemorrhage is not commonly seen in clinical practice. Subarachnoid hemorrhage accounts for $1-7 \%$ of all intracranial hemorrhage [1]. The most common cause of subarachnoid hemorrhage is a head injury, etiology of non-traumatic subarachnoid hemorrhage being rupture of a cerebral vascular aneurysm. However, an estimated $15-20 \%$ of all subarachnoid hemorrhage occurs in the absence of intracranial vascular anomalies [2]. Causes of non-traumatic subarachnoid hemorrhage are likely to be

Manuscript submitted October 4, 2018, accepted October 17, 2018

aSri Jayadeva Institute of Cardiovascular Sciences and Research, Bangalore, Karnataka, India

${ }^{\mathrm{b}}$ Corresponding Author: Huliyurdurga Srinivasa Setty Natraj Setty, Sri Jayadeva Institute of Cardiovascular Sciences and Research, 493, 4th Cross, 7th Main, J.P. Nagar 3rd Phase, Bangalore 69, Karnataka, India.

Email: drnatrajsetty75@gmail.com

doi: https://doi.org/10.14740/cr787 multifactorial; and hypertension corresponds with increased risk. Often fatal, the morbidity associated with subarachnoid hemorrhage correlates with the age at onset and extent of the neurologic compromise. CoA which accounts for $5-8 \%$ of congenital heart disease, are rarely associated with intracranial hemorrhage and is usually missed in clinical examination. Here we report a case of a young female with long standing uncontrolled hypertension and subarachnoid hemorrhage, who was incidentally diagnosed to have coarctation of aorta when worked up [3].

\section{Case Report}

A 22-year-old young female presented in outpatient department (OPD) for uncontrolled hypertension from past 3 years, she has a past history of subarachnoid hemorrhage in 2016 for which she underwent craniotomy with right middle cerebral artery aneurysm clipping. On clinical evaluation, she had a blood pressure (BP) of 180/110 mm Hg in both the upper limbs, with no palpable pulses in both the lower limbs, prominent suprasternal pulsations with a systolic murmur in the left side precordium and a soft bruit over the back on both the sides. Her routine blood investigations were within normal limits

Having a possibility of coarctation of aorta, she was subjected for detailed cardiac evaluation. Electrocardiogram (ECG) revealed normal sinus rhythm. 2-D echocardiogram (ECHO) had evidence of coarctation of the aorta (post ductal) with high gradients $(94 \mathrm{~mm} \mathrm{Hg}$ ), normal left ventricular function. Chest X-ray showed signs of bilateral posterior rib notching in the inferior aspect and no evidence of aortic dilatation (Fig. 1). The patient was subjected for computed tomography (CT) aortography for localizing the site and extent of coarctation of aorta which revealed coarctation of aorta 22 $\mathrm{mm}$ caudal to the origin of the left subclavian artery, measuring $4 \mathrm{~mm}$ in length and about $2.3 \mathrm{~mm}$ in caliber. Bilateral extensive collaterals were seen in the scapular, paravertebral and posterior thoracic wall with hypertrophied right internal mammary artery (RIMA), left internal mammary artery (LIMA) and intercoastal arteries. B/L renal arteries were normal (Fig. 


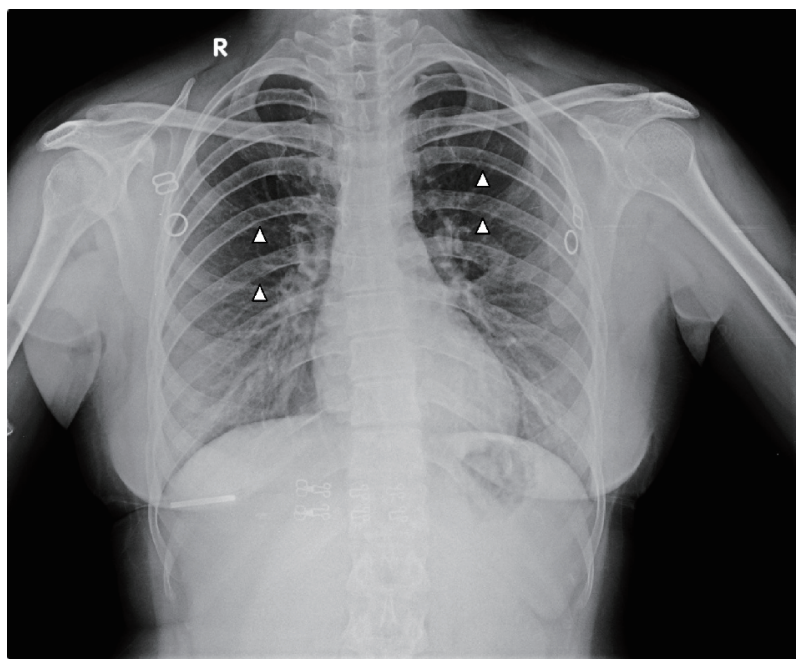

Figure 1. Chest X-ray posteroanterior (PA) view of the patient shows prominent bilateral posterior rib notching in the inferior aspect as shown by arrow heads.

2a-c). The diagnosis of coarctation of the aorta with secondary hypertension was made, and the patient was planned for coarctoplasty. The patient underwent successful coarctoplasty through right femoral artery approach using a Tyshak balloon measuring $15 \times 30 \mathrm{~mm}$ (Fig. 3a, b). The stent was not placed as the results were very good with gradients across the coarctation of aorta reducing from $95 \mathrm{~mm} \mathrm{Hg}$ to $10 \mathrm{~mm} \mathrm{Hg}$ post balloon dilatation. The patient tolerated the procedure well and her BP of both the upper limbs dropped to $130 / 80 \mathrm{~mm} \mathrm{Hg}$ and lower limb systolic BP measured $120 \mathrm{~mm} \mathrm{Hg}$ with easily palpable pulses (Fig. 4).

\section{Discussion}

Coarctation of the aorta is characterized by short-segment narrowing in the region of the ligamentum arteriosum adjacent to the origin of the left subclavian artery. Sometimes the constriction occurs proximal to the subclavian artery when it is called pre-ductal coarctation of aorta. The incidence of coarctation of the aorta is 4 in 10,000 live births. The adult who had surgical repair of coarctation of the aorta as an infant is more likely to have associated cardiac lesions with bicuspid aortic valve, subaortic stenosis, ventricular septal defect, and arch hypoplasia of varying degrees. Five to eight percent of children with congenital heart disease have coarctation of aorta [3].

The defect imposes significant afterload on the left ventricle resulting in wall stress, compensatory left ventricular hypertrophy, left ventricular dysfunction and collateral formation. Coarctation of aorta in adults usually presents as systemic hypertension and discrepancy between upper limb and lower limb blood pressure as in our case.

The coarctation of the aorta may be demonstrated on a suprasternal notch view of the aortic arch and proximal descending aorta, which, when combined with color flow imaging and continuous-wave spectral Doppler interrogation, may demonstrate turbulence in the proximal descending aorta and show the characteristic flow profile of forwarding diastolic flow. An abnormal Doppler flow pattern may also be noted in the abdominal aorta, i.e. decreased pulsatility and absence of early diastolic flow reversal. Abnormal flow in collateral vessels can be detected by color flow and pulse Doppler.

The natural history of unrepaired coarctation of the aorta includes the development of systemic hypertension and subsequent morbidity and death from cardiovascular disease [4]. The age at correction is the most important factor for the relief of hypertension and long-term survival [5]. The incidence of spontaneous subarachnoid hemorrhage is reported to be around 10.5 per 100,000 person-years; and the leading cause of spontaneous subarachnoid hemorrhage is the rupture of an intracranial aneurysm, which accounts for about $80 \%$ of cases and has a high rate of death and complications [6].
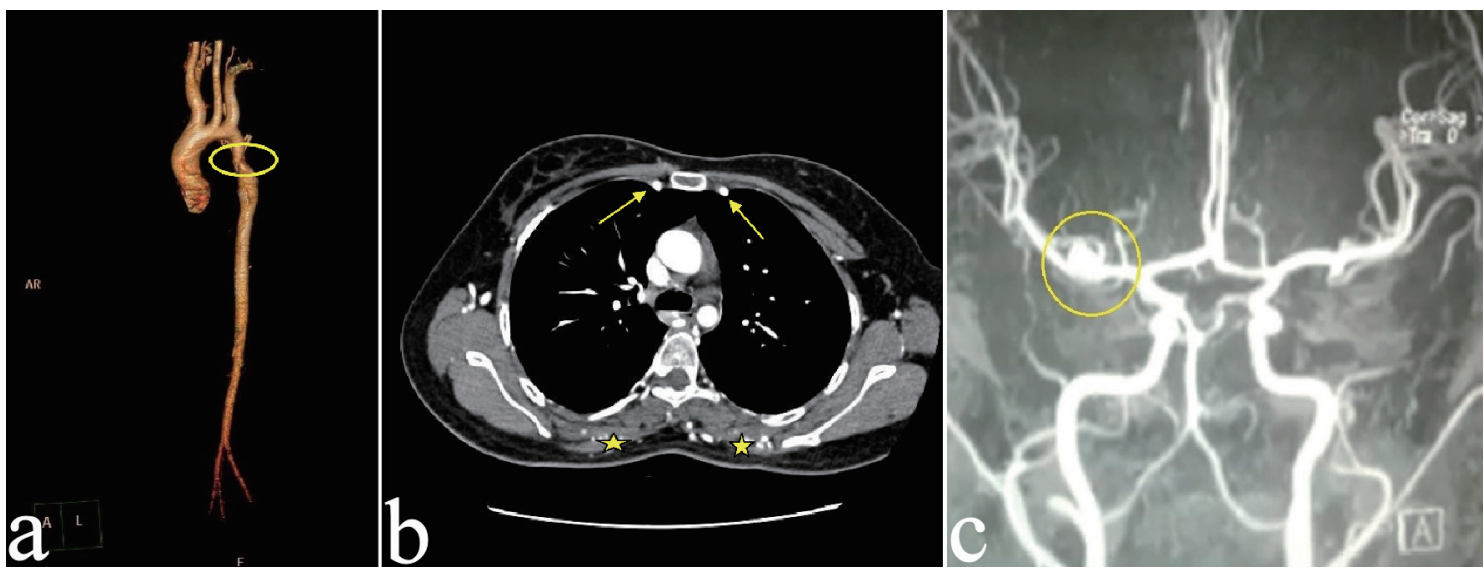

Figure 2. (a) CT aortography showing coarctation of aorta with a shelf like appearances is noted about $22 \mathrm{~mm}$ caudal to the origin of the left subclavian artery, measuring $4 \mathrm{~mm}$ in length and about $2.3 \mathrm{~mm}$ in caliber. (b) Contrast-enhanced computed tomography (CECT) thorax showing prominent RIMA and LIMA (yellow arrows) with prominent extensive collaterals seen around bilateral scapular region (yellow stars). (c) Magnetic resonance imaging (MRI) showed superolaterally directed right middle cerebral artery (MCA) bifurcation aneurysm measuring $6.3 \times 4.5 \mathrm{~mm}$. RIMA: right internal mammary artery; LIMA: left internal mammary artery. 


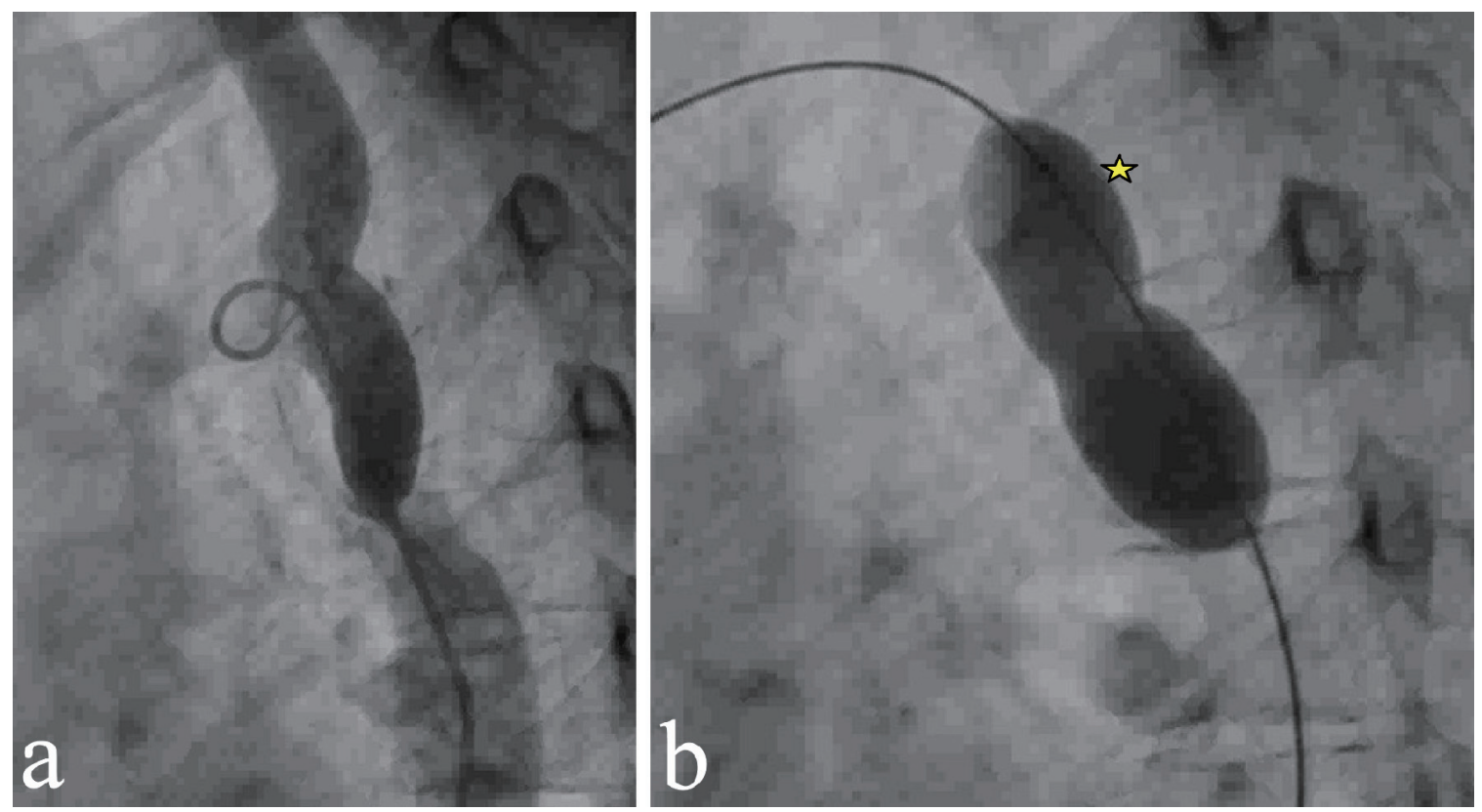

Figure 3. (a) Arch angiography showed discrete coarctation of the aorta distal to the left subclavian artery. (b) Arch angiography showed $15 \times 30 \mathrm{~mm}$ measuring Tyshak balloon (star) was passed over Terumo wire and inflated across the stenotic segment.

In patients with coarctation of the aorta, intracerebral or subarachnoid hemorrhage is more common in the second and third decades. The risk of serious neurological complications associated with coarctation of the aorta and the resultant proximal hypertension mandates early diagnosis and treatment. Berry aneurysms are reported to occur in $10 \%$ of patients with coarctation of aorta and this has been related both to the high pressure of the vascular tree proximal to the coarctation

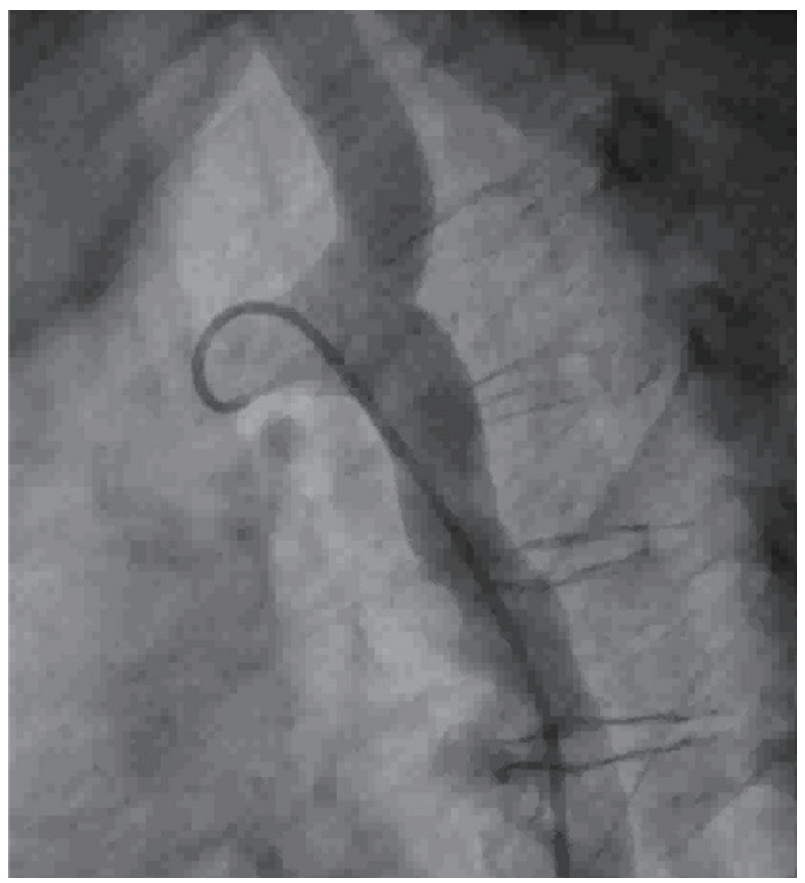

Figure 4. Arch angiography showed final results with good results. of the aorta and to congenital defects of the vascular tree [7]. The 2008 American Heart Association/American College of Cardiology guidelines for intervention in coarctation of aorta includes peak to peak coarctation of aorta gradient $\geq 20 \mathrm{~mm}$ $\mathrm{Hg}$ or peak to peak coarctation of aorta gradient $<20 \mathrm{~mm} \mathrm{Hg}$ in presence of anatomic imaging revealing significant coarctation of the aorta. The European Society of Cardiology recommends early treatment in all patients with a non-invasive pressure difference of more than $20 \mathrm{~mm} \mathrm{Hg}$ in upper and lower limbs regardless of symptoms but with upper limb hypertension $>140 / 90 \mathrm{~mm} \mathrm{Hg}$ and significant left ventricular hypertrophy [8]. Balloon angioplasty was introduced in 1982 and is currently done with or without stent deployment. It is the preferred treatment modality in native coarctation of the aorta in adults or re-coarctation of the aorta after surgery [9]. There is an increased incidence of an aneurysm and restenosis after balloon angioplasty. Despite successful repair of coarctation of the aorta, recurrent hypertension is common during long-term follow-up. In this case, we have performed a successful balloon dilatation only with very good results and the patient is doing well on follow-up.

\section{Conclusions}

The risk of cerebrovascular complications associated with coarctation of the aorta and resultant hypertension mandates early diagnosis and treatment. Intracranial aneurysm rupture associated with coarctation of the aorta, most likely due to the high early mortality in untreated cases. A ruptured intracranial aneurysm can be successfully treated with surgery or clipping of an aneurysm. In our case, patient successfully underwent right pterional craniotomy, clipping of an aneurysm and bal- 
loon dilatation of coarctation of the aorta with excellent outcomes.

\section{Acknowledgments}

None to declare.

\section{Financial Disclosure}

None to declare.

\section{Conflict of Interest}

None to declare.

\section{Informed Consent}

Not applicable.

\section{Author Contributions}

Huliyurdurga Srinivasa Setty Natraj Setty: study design, data collection, manuscript preparation, literature search; Shivanand S. Patil: literature search; Narendhiran Pandurangan: literature search; Veeresh Patil:data collection; Jayashree Kharge: data collection; Tagatagere Ramegowda Raghu: data interpretation; Rahul Patil: study design and manuscript preparation; Bachahalli Krishnanayak Geetha: literature search; Sathwik Raj: data collection; Cholanahalli Nanjappa Manju- nath: data interpretation.

\section{References}

1. Feigin VL, Lawes CM, Bennett DA, Anderson CS. Stroke epidemiology: a review of population-based studies of incidence, prevalence, and case-fatality in the late 20th century. Lancet Neurol. 2003;2(1):4353.

2. Bonita R. Cigarette smoking, hypertension and the risk of subarachnoid hemorrhage: a population-based casecontrol study. Stroke. 1986;17(5):831-835.

3. Hoffman JI, Kaplan S. The incidence of congenital heart disease. J Am Coll Cardiol. 2002;39(12):1890-1900.

4. Campbell M. Natural history of coarctation of the aorta. Br Heart J. 1970;32(5):633-640.

5. Brouwer RM, Erasmus ME, Ebels T, Eijgelaar A. Influence of age on survival, late hypertension, and recoarctation in elective aortic coarctation repair. Including longterm results after elective aortic coarctation repair with a follow-up from 25 to 44 years. J Thorac Cardiovasc Surg. 1994;108(3):525-531.

6. Suarez JI, Tarr RW, Selman WR. Aneurysmal subarachnoid hemorrhage. N Engl J Med. 2006;354(4):387-396.

7. Benyounes N, Blanc R, Boissonnet H, Piotin M. Subarachnoid hemorrhage revealing aortic coarctation in a young man. Neuroradiology. 2011;53(11):931-932.

8. Baumgartner H, Bonhoeffer P, De Groot NM, de Haan F, Deanfield JE, Galie N, Gatzoulis MA, et al. ESC Guidelines for the management of grown-up congenital heart disease (new version 2010). Eur Heart J. 2010;31(23):2915-2957.

9. Lorber A, Ettedgui JA, Baker EJ, Jones OD, Reidy J, Tynan M. Balloon aortoplasty for recoarctation following the subclavian flap operation. Int J Cardiol. 1986;10(1):57-63. 